\title{
Narrar con imágenes: entrevistas fotográficas en un estudio comparado de "resiliencia" social y resistencia ante la crisis
}

Telling stories with images: photographic interviews in a comparative research on social "resilience" and resistance to the crisis

\author{
ARACELI SERRANO \\ Universidad Complutense de Madrid \\ aserrano@ucm.es (ESPAÑA) \\ JUAN CARLOS REVILLA \\ Universidad Complutense de Madrid \\ jcrevilla@cps.ucm.es (ESPAÑA)

\section{MARÍA ARNAL} \\ Universidad Complutense de Madrid \\ m.arnal@cps.ucm.es (ESPAÑA)
}

Recibido: 04072016

Aceptado: 06092016

\section{RESUMEN}

En este artículo se presenta una reflexión metodológica sobre la utilización de la entrevista fotográfica en un estudio sobre las estrategias sociales, culturales y comunitarias de "resiliencia" de los hogares fuertemente afectados por la crisis económica y social actual. Esta investigación se realizó en el marco del proyecto europeo RESCuE en el que participan nueve países que se han visto afectados en distinto grado por la crisis. En el artículo se reflexiona sobre las aportaciones y el enriquecimiento que ha posibilitado esta técnica en la investigación, permitiendo un mayor y más diverso acercamiento a las narraciones sobre las prácticas de resiliencia (individual, grupal, comunitaria), así como en torno a las interpretaciones y vivencias sobre estas prácticas en el ámbito cotidiano de los sujetos, con 
mayor posibilidad de internacionalización del material y los resultados. También se profundiza en las limitaciones y obstáculos de la entrevista fotográfica en la investigación realizada, reflexionando sobre las precauciones a adoptar en el diseño y dinámica de aplicación de esta técnica, de manera que no limite las múltiples potencialidades que la foto-elicitación ofrece.

\title{
PALABRAS CLAVE
}

Entrevista fotográfica; foto-elicitación; fotovoz; crisis; estrategias familiares; resiliencia, Proyecto RESCuE

\begin{abstract}
This methodological article analyses the use of the photographic interview in a study of social, cultural and communitarian household strategies of "resilience" during the current economic and social crisis. The research was carried out in the framework of the European project RESCuE with the participation of nine European countries differently affected by the crisis. The text reflects on the contributions and the enrichment that the use of the technique had made possible: more and more diverse ways of telling about practices of resilience (individual, group relationed and communitarian), experiences and interpretations in everyday life and the chance to internationally compare materials and results. Furthermore, the limits and obstacles to the use of the photographic interview in our research are fully analyzed, together with the consideration of the precautions to take during the design and implementation of this technique in a way to avoid the limitations to the potentialities that photo-elicitation offers.
\end{abstract}

\section{KEY WORDS}

Photographic interview; photo-elicitation, photovoice; crisis; family strategies; social resilience; RESCuE Project.

\section{INTRODUCCIÓN}

Durante la segunda mitad del siglo XX y hasta el momento actual, ha sido progresiva e imparable la incorporación de materiales visuales a la investigación social. En primer lugar, desde la Antropología y las Ciencias de la Comunicación, en segundo, desde la Sociología, la Ciencia Política y la Educación, las investigaciones que incorporan materiales visuales se multiplican y se consolida su espacio de pertinencia, tanto en el ámbito académico (más renuente históricamente a esta incorporación), como en el ámbito de la investigación social y política aplicada. Muchas han sido las formas de trabajo 
con dichos materiales visuales: desde su incorporación como materiales secundarios, elaborados desde los diversos espacios culturales, institucionales o políticos, hasta la producción de materiales ad-hoc orientados a cubrir unos objetivos de investigación: elaboración de vídeos, fotografías, dibujos, mapas, etc. ${ }^{1}$ Una de las líneas de trabajo más prolíficas en este ámbito se relaciona con la incorporación de estos materiales visuales a los viejos dispositivos de investigación: encuestas con apoyo gráfico y opciones de respuesta fotográficas, grupos de discusión que debaten en torno a vídeos, fotografías, publicidades; trabajo etnográfico que se registra en formato audiovisual o que se relata con este mismo formato o entrevistas que se desarrollan con el apoyo y estímulo de material gráfico. Es, precisamente, a este espacio que incorpora el material fotográfico al dispositivo conversacional de la entrevista al que se dedica el presente artículo.

En este texto se da cuenta de la reflexión metodológica generada a partir de un estudio europeo ${ }^{2}$ centrado en el análisis de las estrategias sociales, culturales y comunitarias de "resiliencia" social y resistencia que desarrollan los hogares ante los efectos de la reciente crisis económica y social. Mediante una aproximación cualitativa que combina trabajo etnográfico, entrevistas a informantes clave y entrevistas orales y fotográficas a familias fuertemente afectadas por la crisis, se comparan las estrategias desplegadas en España, Portugal, Grecia, Reino Unido, Alemania, Polonia, Irlanda, Finlandia y Turquía. Se pretende reflexionar sobre el uso, relativamente novedoso en el contexto español (aunque ampliamente consolidado en contextos anglosajones) de la entrevista fotográfica. La investigación de la que aquí se da cuenta permite debatir la experiencia práctica, las potencialidades, los efectos de sentido, así como los problemas del uso del dispositivo, comparando varios países, hábitats (entornos urbanos y rurales), grupos autóctonos e inmigrantes, grupos generacionales, así como introducir la dimensión de género a la hora de dar cuenta del funcionamiento de esta práctica. El hecho de que con los hogares entrevistados en el proyecto se hayan desplegado dos entrevistas diferentes, una desarrollada al modo convencional haciendo uso del lenguaje oral y una segunda centrada en el comentario e interpretación de fotografías realizadas por dichas familias (en un uso de la técnica que ha venido a llamarse entrevistas fotográficas auto-conducidas, tras una demanda organizada temáticamente), nos permitirá comparar ambos usos de la técnica de la entrevista.

1 Remitimos, también, a la sugerente distinción que establece Davila (2015: 307 y 312) entre "Sociología sobre fotografía(s)" y "Sociología con fotografía(s)".

2 Proyecto RESCuE (Patterns of Resilience during Socioeconomic Crises among Households in Europe) del VII Programa Marco de Investigación y desarrollo tecnológico Europeo. Unión Europea. Programa "Socio-economic Sciences and Humanities-SSH", Citizens' resilience in times of crisis, Referencia: FP7-SSH-2013-2. 


\section{MARCO TEÓRICO-CONCEPTUAL: DEBATES, REFERENTES Y PRÁCTICAS EN TORNO A LA ENTREVISTA FOTOGRÁFICA}

Bajo la etiqueta de entrevista fotográfica se incluyen diversas prácticas que se relacionan con la incorporación de material fotográfico al dispositivo conversacional de la entrevista abierta. El objetivo de la técnica es considerar cómo los sujetos elaboran discurso oral tras la presentación de imágenes fotográficas, aportando sus propias perspectivas y puntos de vista, cómo narran sus vivencias junto con las imágenes, pero también se centra en considerar cómo toman, ilustran, condensan, jerarquizan en imágenes dichas vivencias, experiencias, sentimientos y cómo lo hacen desde su propio punto de vista ${ }^{3}$. Estas fotografías, bien presentadas a los sujetos entrevistados, bien construidas por ellos mismos, se acompañan de discurso verbal en relación a dichas fotografías, en su interpretación, en sus evocaciones o en el relato de su proceso de construcción. Así, los sujetos expresan sus subjetividades, identidades y vivencias, tanto oralmente a través de su discurso verbal, como icónicamente a través de sus fotografías, con sus composiciones, su enfoque, sus planos, su selección de objetos, sujetos, escenarios o bien mediando la interpretación de las fotografías elaboradas por otros. El tipo de significados, procesos de selección y sentimientos que se activan y que se potencian, así como la multimodalidad e intertextualidad de los lenguajes involucrados en la comunicación, complementan y/o aportan nuevas perspectivas si lo comparamos con la entrevista centrada exclusivamente en el lenguaje verbal.

Este dispositivo que vamos a denominar entrevista fotográfica cuenta ya con una dilatada experiencia y un acervo importante de trabajo empírico que ha tratado de extraer sus potencialidades y reflexionar sobre su práctica. $\mathrm{Si}$ bien el uso de esta técnica se ha desarrollado fundamentalmente en contextos anglosajones (Collier \& Collier, 1986; Ziller, 1990; Wang \& Burris, 1997; Harper, 2002; Rasmussen, 2004; Clark-Ibáñez, 2004; Noland 2006; Kaplan, et al. 2007; Thomson y Gunter 2007; Kolb, 2008; Jenkings, Woodward \& Winter, 2008; Pink, 2008; Allen, 2011 y 2012; Smith, Gidlow \& Steel, 2012; Sharon \& Kinsella, 2013; Miller, 2014 o Creighton et al., 2015), cada vez tiene más presencia en otros contextos. Sin embargo, su uso es poco frecuente en la investigación social en España, donde apenas encontramos algunos ejemplos y referencias (Arias, 2011; Coronell y Rodríguez, 2013; Rabadán y Contreras, 2014; Davila, 2015; Escalante, 2015; Soriano y Cala, 2016). Uno de los ámbitos donde más se ha desarrollado la técnic a en el contexto español es en el de la intervención socioeducativa y socio-sanitaria, así como en el de la reconstrucción de la memoria histórica.

3 No hay que olvidar, junto con Davila (2015: 306-307), que "la práctica fotográfica no solo registra imágenes de lugares y situaciones, sino que también les da forma, expresando el imaginario tanto de aquello que se fotografía, como de quien lo fotografía y de quienes interpretan tal fotografía". 
Si bien en un primer momento la técnica de la foto-entrevista se utilizó desde su dimensión fundamentalmente informativa y extractiva y se etiquetó bajo el concepto photo-elicitation interview (entrevista de estimulación fotográfica), en su desarrollo, poco a poco, los usos y sentidos de la técnica han ido ampliándose hasta encontrarnos, en el momento actual, con una multiplicación de las denominaciones bajo las cuales se ha considerado esta práctica: entrevista de foto-provocación, photo-elicitation interview (entrevista de foto-estimulación), foto-entrevista, entrevista fotográfica auto-conducida, entrevista fotográfica participativa o photo-voice, son algunos de los nombres con los cuales se le ha designado. Cada uno de estos nombres guarda estrecha relación con algún tipo de dimensión que se entresaca, con algún uso específico de las fotografías en el proceso, así como con un posicionamiento epistemológico que remite a las funciones desempeñadas por la propia investigación. Generalmente, se utiliza el término foto-provocación cuando las fotografías no son producidas por los propios sujetos, sino que son aportadas por el equipo de investigación; ante ellas se solicita a los sujetos que comenten qué les sugiere o qué les evoca. Quizá el concepto más difundido sea el anglosajón photo-elicitation, cuyo significado se ha ido ampliando, desde el sentido de estimulación fotográfica con el que inicialmente se pensó ${ }^{4}$, hasta abarcar, también, espacios en los que las fotografías son aportadas desde la propia vivencia del entrevistado y, con mayor frecuencia, fotografías que son hechas, siguiendo los objetivos de la investigación, por parte del propio entrevistado. Además, en esta acepción, se incorpora el análisis del contexto interaccional a través del uso híbrido de lenguajes icónico y verbal y del espacio de mediación introducido por las fotografías, que lo diferencia de la entrevista centrada exclusivamente en la interacción verbal. La potencialidad de que sean los propios sujetos entrevistados los que crean, proponen y seleccionan sus propias fotografías ha generado también su propia etiqueta (autodriven photography, Heisley \& Levy, 1991), como una modalidad más participativa de desarrollar la técnica ${ }^{5}$. Por último, es la acepción más reciente, photovoice $^{6}$ o fotovoz (no restringida al uso en situación de entrevista), la que sirve para hacer referencia a la opción de investigación más frecuente en aproximaciones transformadoras (integradas en acercamientos epistemológicos críticos y participativos) en los que el hecho de hacer fotografías por parte de los sujetos no es una manera de extraer información o de modificar los

\footnotetext{
${ }^{4}$ Una de las traducciones más relevantes del concepto "elicitation" es también el de sonsacamiento

${ }^{5}$ Hurworth (2003) señala una etiqueta más, vinculada a esta última, que denomina Photo Novella que se centra en dar cámaras a los grupos sociales que se estudia para que fotografíen escenas de su vida cotidiana, de su día a día y, posteriormente, en situación de entrevista construyan un relato sobre su cotidianeidad. Este fue el nombre que las autoras pioneras en el uso de la técnica del photo-voice, fundamentalmente en el ámbito de la salud, emplearon inicialmente para denominarla.

${ }^{6}$ En España se conoce también como entrevista fotográfica participativa, que ha constituido una herramienta básica en la Investigación-acción participativa (IAP). Su uso se ha extendido, fundamentalmente, en el ámbito del desarrollo comunitario, la salud pública y la educación.
} 
espacios comunicativos, sino una forma de reflexionar, intercambiar, fomentar la participación y el debate, tomar conciencia y visibilizar problemas y grupos, en un planteamiento investigador orientado hacia la transformación social y el empoderamiento (Luna, 2009) de los grupos y comunidades que participan. Wang \& Burris (1997), Wang (1999) y Wang et al. (2000), referentes clásicos en esta variante de la técnica, lo definen como un proceso por el que los sujetos pueden identificar, representar y concienciar a su propia comunidad a través de la discusión y el debate generado en torno a y fomentado por las fotografías ${ }^{7}$, así como por su capacidad de llegar con este medio a los legisladores y responsables de políticas públicas. En este objetivo, acompañado por el uso de la fotografía participativa, confluyen tanto investigadores como activistas sociales de muy diversos espacios y culturas ${ }^{8}$. El uso se ha ido ampliando hasta encontrar, hoy en día, variados textos recopilatorios de experiencias a lo largo y ancho del planeta, así como guías didácticas sobre su uso. Por ejemplo, Ewald \& Lightfoot (2005) recogen en su texto más de treinta años de experiencia practicando Photovoice, al tiempo que aportan una auténtica guía a los usuarios potenciales. Un reciente texto en castellano (Soriano y Cala, 2016) hace un exhaustivo recorrido en esta misma línea.

En términos generales, se puede observar cómo, en sus diversas modalidades, el uso de la entrevista fotográfica se dirige a grupos que presentan más dificultades en su expresión oral o que su modo de comunicar pasa fundamentalmente por la imagen (especialmente en las sociedades contemporáneas): niños, adolescentes y jóvenes, así como población en desventaja (minorías étnicas, personas en situación de pobreza, personas con discapacidad, personas viviendo en la calle, etc.) y/o algo muy frecuente, en grupos que reúnen ambas características etáreas y de desventaja social: niños trabajadores (Bolton, Pole \& Mizen, 2001), jóvenes en situación de calle (Joanau, 2009), niños en la calle (Campos y Dollinger, 1998; Mizen \& Ofosukusi, 2007; Young \& Barret, 2001), estudiantes de secundaria residentes en barrios pobres (Meo y Dabenigno, 2011), niños con cáncer (Epstein et al., 2006), padres de niños en escuela infantil de sectores desfavorecidos (Miller, 2014), mujeres jóvenes afroamericanas en situación de calle (Killion and Wang, 2000), jóvenes negros de clase media (Allen, 2012), jóvenes con discapacidad (Gibson et al., 2013) o trabajadoras del sexo (Barlow \& Hurlock, 2013). Señalan algunos

${ }^{7}$ De hecho, el propio nombre Photovoice, juega con el doble sentido de VOICE como voz y como acrónico de "Voicing Our Individual and Collective Experience" (Davila, 2015:321).

${ }^{8}$ Rabadán y Contreras señalan que "organizaciones sin fines de lucro como Photovoice, en Inglaterra, Asha Nepal, Bridges to Understanding y Click on Hearts en EEUU, Foto Kids Guatemala, Aecha Paraguay, Photo-voice Singapur, y, en España, organizaciones como Imagen Acción, Fotovoz, youPHOTO y colectivos como Nophoto, entre otras, han utilizado no solo la fotografía, sino también otros métodos visuales, como el vídeo, para trabajar junto a niños, adolescentes y mujeres, para lograr que sus voces sean escuchadas y sirvan de ayuda para tomar conciencia del poder que tienen para cambiar su realidad" (2014:145). Existe, además, una multiplicidad de proyectos de intervención comunitaria promovidos por asociaciones y ONGs basados en la técnica de la Fotovoz (ver, por ejemplo, el de la Asociación Create Your Voice; www. createyourvoice.org). 
autores (Epstein et al., 2006; Creighton, Brussoni, Oliffe \& Han, 2015) que esta técnica puede contribuir a aliviar ansiedad cuando se trata de temas complicados como la muerte, la enfermedad o la pobreza.

Además de estos ámbitos temáticos y estas poblaciones, se ha tendido a utilizar con variadas intencionalidades y en muy diversas temáticas. Analizar el cambio social en contextos rurales y urbanos, profundizar en torno a la construcción de identidades colectivas, investigar en el área de la salud o la educación, estudios evaluativos sobre programas sociales, investigación de mercados y comportamiento del consumidor o participación medioambiental son algunos de los espacios adicionales en los que más frecuentemente encontramos aplicado este tipo de dispositivo.

Si atendemos a cómo se ha ido introduciendo esta práctica en el espacio de la Metodología de las Ciencias Sociales, podemos observar cómo la técnica de la foto-entrevista fue utilizada muy tempranamente por los primeros antropólogos a principios del siglo XX en sus etnografías, utilizando fotografías sobre rituales para entrevistar a sus informantes clave y hacerlos hablar, $\mathrm{y}$, de hecho, es una práctica con frecuencia presente en las prácticas antropológicas en general, si bien en contadas ocasiones se ha presentado como una técnica con entidad propia y con su espacio de reflexión particular (Harper, 2002). Fue John Collier en 1967 un autor pionero en el uso y reflexión sobre esta técnica ${ }^{9}$, aunque, en su consideración, ésta se proponía al servicio del trabajo etnográfico y no como una técnica con entidad propia. Estos autores la concibieron como una forma de establecer puentes entre el investigador y el entrevistado, entre los mundos familiar y desconocido de ambos sujetos en la situación de interacción que supone la entrevista. Si bien estos autores clásicos y pioneros continúan siendo, hoy en día, alguna de sus fundamentales referencias, varios autores han señalado que su aportación constituyó más bien una introducción y una ejemplificación de su uso, pero que los aspectos teóricos y metodológicos de este dispositivo quedaron en su obra sin ser desarrollados.

\footnotetext{
${ }^{9}$ Previamente, este autor comenzó en 1957 a probar su potencialidad estudiando aspectos relacionados con la salud mental de comunidades en transformación. Posteriormente, en un equipo más amplio, desarrolló un experimento estudiando cómo determinadas familias se adaptaban a nuevos vecindarios étnicamente mezclados y a nuevos contextos laborales en fábricas. Para ello desarrollaron entrevistas fotográficas y entrevistas únicamente verbales para poder comparar la potencialidad de ambas aproximaciones. Una reflexión ampliada sobre este experimento fue publicada por Collier \& Collier (1986). Si bien son los Collier los autores clásicos a quienes se atribuyen las primeras reflexiones sobre la técnica de la foto-entrevista, no seríamos justos si no reconocemos la gran aportación que supuso en los años 60 y 70 del siglo XX los experimentos de cámara nativa que se desarrollaron en el seno de la Antropología; en ellos, los propios sujetos investigados llevaban la iniciativa del rodaje o la fotografía y manejaban sus instrumentos. Worth y Adair (1972), por ejemplo, plantean una aproximación a los navajo a partir de su propia producción de imágenes, formándolos, primeramente, en talleres de vídeo, que pudieran habilitar a sus protagonistas en la elaboración de estas imágenes. En estos experimentos se hace una propuesta de etnografía desde dentro (la auto-etnografía) como una opción para restituir a los filmados, no solo su voz, sino también su cosmovisión.
} 
Harper (2002) ${ }^{10}$ y, especialmente, Lapenta (2004) son algunos de los autores que mejor han desplegado estos aspectos. Este último, más que centrarse en una descripción de la técnica o en su ejemplificación, intenta reflexionar sobre las razones potenciales de su uso. Así, entresaca un primer valor informacional, pues la situación de la foto-entrevista contribuye a posibilitar una reconstrucción más completa del contexto en el que el sujeto entrevistado se sitúa (2004:11); destaca también su capacidad de registrar y reflejar personas, objetos, situaciones, entornos, etc., así como facilitar la reflexión, la discusión y el debate con el propio sujeto entrevistado en torno a los contenidos y las interpretaciones hechas a partir de las fotografías; además, posibilitaría que se fomente el debate con otros investigadores en torno a esos registros e interpretaciones del contexto. Siguiendo a este autor, en la propia situación de interacción con el entrevistado se establece un nuevo contexto comunicativo en el que la interacción está mediada por elementos que van más allá de la comunicación verbal, esto es, por las fotografías, que posibilitan una gestión diferente de la dinámica de la entrevista. En esta distinta dinámica, se rompe la estructura linguiística unidimensional a través de la introducción de una nueva dimensión comunicativa y la mediación de un tercer elemento interviniente (las fotografías). De esta manera, se suplementan los indicios y elementos en juego en la interacción y se transforma la misma estructura de la comunicación verbal en un nuevo espacio comunicativo, en parte, gracias al carácter proyectivo, polisémico e indeterminado de la imagen. En esta dinámica, los elementos de carácter icónico que se introducen condicionan, en buena medida, el proceso de construcción y negociación de sentido, de negociación de identidades, de establecimiento de (a)simetrías entre el entrevistador y el entrevistado. Al ser las fotografías muestras, a veces más concretas, a veces más simbólicas, de lo que se ilustra en el discurso verbal el proceso de interacción se vuelve más negociado, más reflexivo y las asimetrías entre entrevistador y entrevistado se ven, en ocasiones, alteradas (Lapenta, 2003). En estas circunstancias se consiguen comunicaciones más largas, más detalladas y expandidas en temas y detalles (Lapenta, 2004; Hurworth, 2003).

Algunas otras potencialidades que se atribuyen a la entrevista fotográfica tienen que ver con la más fácil implicación de sujetos en la investigación (Warren, 2005; Kolb, 2008; Meo y Dabenigno, 2011) o la facilitación del diálogo y la comunicación en los primeros momentos, habitualmente más

\footnotetext{
${ }^{10}$ Harper, además de reflexionar sobre las potencialidades de la técnica, ofrece una amplia y sistemática revisión sobre el conjunto de investigaciones que pudo localizar entre 1986 y 2001 que se basaban en el uso de la entrevista fotográfica y realiza una especie de clasificación, organización y comentario sobre las grandes áreas en las cuales se localizaban: estudios sobre clases sociales y organización familiar; etnografías de comunidades; estudios sobre identidades y biográficas y estudios culturales (2002: 16). Además de la reflexión metodológica, también Harper destaca por el uso empírico de dicha técnica en investigaciones como la que desarrolla junto con Faccioli en The Italian way. Food and social life (Harper \& Faccioli, 2010), donde plantean una investigación en la que se incluyen muy diversos usos de las fotografías (tanto las realizadas por los investigadores, como por los propios sujetos investigados).
} 
tensos, del desarrollo de la entrevista (Meo y Dabenigno, 2011; Hurworth, 2003). En otras ocasiones se entresaca su potencialidad para conseguir una comunicación más íntima, donde las emociones y los sentimientos emerjan con mayor facilidad (Harper, 2002; Creighton, Brussoni, Oliffe \& Han, 2015). Se menciona también la oportunidad que supone a la hora de posibilitar la entrada en espacios cotidianos, privados e íntimos de otra manera inaccesibles para el investigador, de manera que dichos espacios queden reflejados en imágenes (Meo y Dabenigno, 2011). Permite, asimismo, contar con otras perspectivas y puntos de vista, según son seleccionados y jerarquizados por los propios entrevistados y plasmados en imágenes, al tiempo que fomenta el recuerdo y activa la memoria cuando se usan fotografías provenientes del pasado o ancladas en vivencias pasadas (Harper, 2002; Meo y Dabenigno, 2011; Hurworth, 2003). Por otra parte, se señala que esta técnica permite un mejor acceso a los espacios de la movilidad -espacial- de los sujetos al quedar incorporados en las imágenes (Pink, 2008). También se apunta la potencialidad de facilitar el desarrollo de la confianza y de la comunicación intercultural, así como entre grupos diversos, contribuyendo a tender puentes culturales (Banks 2001; Hurworth, 2003) y de posibilitar dar la voz a los sujetos, que, en función de las fotografías, no solo toman la palabra, sino que pueden tener un mayor control de la entrevista, al tener más recursos y elementos para establecer la agenda, el guion, el orden, el marco en el que construyen el relato. Meo y Dabenigno (2011) señalan que la técnica no garantiza por sí misma un carácter más participativo y activo a la investigación, sino que es necesario potenciarlo en su desarrollo. Algunos autores, asimismo, han alertado sobre la mirada romántica del potencial transformador de este tipo de metodologías, donde, en muchas ocasiones, se presenta la cuestión en términos binarios de "dar la voz" o "silenciar", cuando el proceso es mucho más complejo y encierra cuestiones graduales y matizadas de poder, no siempre evidentes (Lykes et al, 2003). En otros espacios se señala, además, que esta técnica enriquece la comunicación y la interpretación de los datos (Galman 2009; Prosser 1992; Banks 2001; Wang et. al. 1996). También se refiere que puede considerarse como un medio de verificación de la información obtenida mediante métodos orales (Hurworth, 2003, lo propone como una forma de triangulación), así como una forma de facilitar las comparaciones inter-culturales consiguiendo un lenguaje común (Ziller, 1990; Douglas, 1998) o como un medio para activar reflexiones sobre la configuración de la memoria colectiva (Ramírez Corzo, 2007).

Además de la prolífica reflexión sobre las potencialidades de la técnica, también está presente, en buena medida, una interesante reflexión sobre sus límites y dilemas éticos, que se relacionan, fundamentalmente, con la necesidad de preservar el anonimato de los sujetos que participan (asunto que se complica con las imágenes), la obligación de la firma de un consentimiento informado para el uso público de las fotografías, la necesidad de explicitar dónde y cómo serán publicadas en el caso de que lo sean, la necesidad del reconocimiento de la autoría de las fotografías cuando son tomadas por los propios sujetos (principio que entra en colisión con el de garantía de anonimato), así como la conveniencia 
de ser especialmente sensibles y cautelosos a la hora de pedir la participación en el estudio evitando intrusiones, constreñimientos o imposiciones. De la misma manera, es necesaria una especial atención y respeto para preservar los espacios de intimidad que el sujeto participante quiera mantener velados, silenciados u ocultos de la publicidad que suponen su reflejo en imágenes. Asimismo, como ya se ha hecho referencia, hay un amplio debate que se desarrolla en relación al tipo de relaciones (simétricas o asimétricas; empoderadoras o de poder sobre el entrevistado) que resulta de gran interés (Epstein et al, 2006; Meo y Dabenigno, 2011; Bridger, 2013).

\section{LA METODOLOGÍA DEL PROYECTO RESCUE Y EL USO DE LA ENTREVISTA FOTOGRÁFICA}

El principal objetivo del proyecto RESCuE es identificar y comprender las estrategias y prácticas culturales, sociales y comunitarias de resiliencia de los hogares afectados por la crisis socioeconómica en los diferentes países europeos objeto de estudio. Para ello se analizan las condiciones y el marco institucional en el que se desenvuelven e interactúan los sujetos, atendiendo a los distintos recursos con los que cuentan los hogares: bienes raíces, capital financiero, conocimientos, prácticas y vínculos sociales (con la familia, amigos, redes sociales comunitarias o globales en las que participa, incluidas instituciones gubernamentales y no gubernamentales con las que se mantenga contacto). Al mismo tiempo, se aborda la vivencia e interpretación que sobre dichas prácticas tienen los hogares. Todo ello se desarrolla desde una perspectiva comparada, pues incluye países en distinta situación socioeconómica, con modelos de Estados de Bienestar diferentes, así como distintos habitats (rural y urbano), diferentes tipos de hogares según el número de miembros y ciclo vital, pero también diferente composición por género, etnia, clase y nacionalidad.

El proyecto sigue una estrategia analítica global, incluyendo elementos del contexto económico, social y cultural para desarrollar una comprensión más compleja de la resiliencia social. Se asume que la potencial resiliencia de los hogares radica en los recursos que son capaces de movilizar en sus prácticas cotidianas, así como en la interpretación y uso de dichos recursos. De esta forma, los hogares (y sujetos) aparecen situados, como señala Bourdieu (1998), en un marco de campos y estructuras sociales en los que orientan su acción a partir de sus habitus y capitales grupales. Esto es, partiendo de los hogares, se observan las relaciones de sus miembros con las comunidades y grupos de los que forman parte y que pueden contribuir a resultados resilientes en sus prácticas. En esta perspectiva, se destaca el papel de las instituciones e intervenciones del Estado del Bienestar por su capacidad para amortiguar o agudizar los efectos de la crisis.

El estudio de las estrategias de resiliencia de los hogares se aborda desde el estudio de casos. En cada país, se han elegido dos contextos, uno urbano y otro rural, seleccionados por cada equipo nacional. Los casos de estudio debían 
tener ciertas características similares, como tratarse de áreas bastante afectadas por la crisis, o, al menos, estar relativamente desfavorecidas o deprimidas en la región o el país. En el caso español, se seleccionó una localidad manchega como caso rural y un barrio de una población del área metropolitana madrileña de la zona sur como caso urbano. En cada una de las áreas de estudio se siguió una estrategia metodológica similar, que incluía, por este orden, entrevistas abiertas a informantes clave, observación participante, entrevistas biográficas en los hogares, además de entrevistas fotográficas en una selección de los mismos hogares. En total, se realizaron 48 entrevistas en cada país ( 24 urbanas y 24 rurales), de las cuales 8 fueron entrevistas a informantes clave, 24 entrevistas biográficas a hogares $\mathrm{y}$, al menos, 16 entrevistas fotográficas ${ }^{11}$ (el perfil concreto de los hogares entrevistados figura en el Anexo 1). Es decir, a una parte importante de los hogares seleccionados se les realizó una segunda entrevista, tras una demanda de toma de fotografías que siguieran un guion temático preestablecido que se propuso como sugerencias de ideas inspiradoras; esta entrevista se articuló en torno al comentario, interpretación y reflexión sobre dichas fotografías tomadas y seleccionadas por uno o varios miembros de los hogares.

Figura 1: Diseño metodológico básico en cada uno de los nueve países del proyecto RESCuE

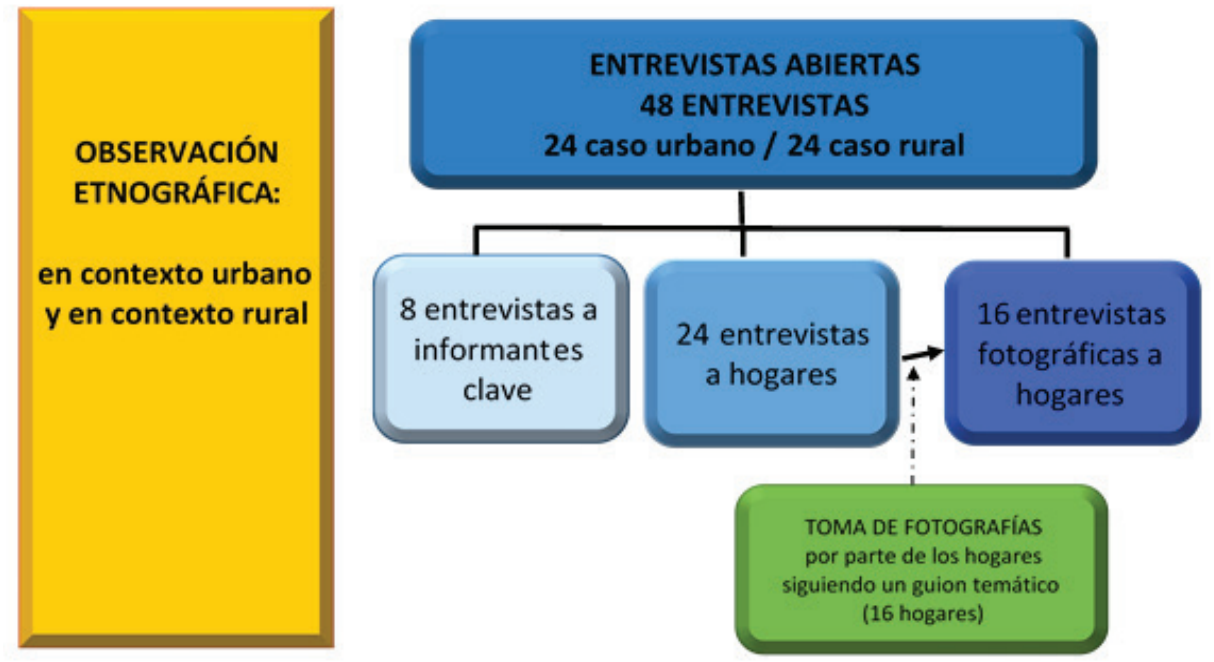

${ }^{11}$ Los números que se señalan son los mínimos establecidos para cada país. El número final de entrevistas, especialmente en el caso de las fotográficas, varió en los diferentes países. En el caso español, finalmente se realizaron veintiuna entrevistas fotográficas (nueve en el caso urbano y doce en el rural). 
Los informantes clave fueron elegidos por ser personas relevantes en las localidades estudiadas, bien por su mayor implicación en la protección o asistencia de hogares afectados, conocimiento de la realidad o capacidad mayor de decisión o influencia en la vida de la comunidad. Son fundamentalmente, personal o directivos de ONGs, asociaciones de vecinos u otras asociaciones y personal de la administración local. Precisamente, la facilidad con la que podrían ser identificados alguno de estos informantes clave explica, en buena medida, la renuncia a mencionar en este texto el nombre de las poblaciones estudiadas. Por otro lado, se buscó la máxima diversidad posible, tanto en la selección de la muestra de hogares e informantes clave, como en las formas de contactación $^{12}$ para, así, conseguir la máxima heterogeneidad discursiva posible. Los entrevistados firmaron impresos de consentimiento, que garantizaban su anonimato y el derecho a ser informados sobre el uso de la información personal recabada, incluidas las fotografías aportadas, así como a retirarse (y retirar sus imágenes) de la investigación si así lo deseaban y en el momento en el que lo desearan.

La inclusión de las entrevistas fotográficas en el proyecto tenía un doble objetivo. En primer lugar, acceder a material visual, objeto de análisis en sí mismo, orientado a producir una autoselección de escenas de la vida cotidiana de los hogares en dificultad, así como de las prácticas cotidianas de resiliencia: cómo viven, trabajan, salen adelante, cómo la crisis está afectando a sus hogares, sus barrios y a las personas con las que viven, así como a sus recursos. Dichas imágenes no fueron importantes solo por su carácter documental ${ }^{13}$, sino también por el tipo de selección, jerarquía e interpretación que dichas prácticas implican, que nos ayudan también a acceder al conjunto de subjetividades, identidades y vivencias implicadas en el proceso de afrontamiento de la crisis. En segundo lugar, las imágenes sirvieron como un estímulo para generar narrativas en las segundas entrevistas con los hogares. Se esperaba, como así ha sido, que se pudieran construir relatos e historias que no saldrían en entrevistas biográficas tradicionales, que suelen dejar fuera algunas cuestiones de detalle que podían ser importantes en el contexto de los objetivos del proyecto. Son esta serie de elementos considerados 'menores', del día a día, los que, muchas veces, aparecen en una fotografía, pero no habitualmente cuando se habla de la propia vida en general. Todo ello contribuye a facilitar el trabajo de campo en sí y a multiplicar los tipos, los contextos de producción y la multimodalidad de los

${ }^{12}$ La contactación se realizó, fundamentalmente, a través de cuatro vías: instituciones públicas (ayuntamientos, trabajadores sociales, albergues, etc.), ONGs y sociedad civil (parroquias, comedores sociales, asociaciones...), bola de nieve (esto es, personas que conocen a otras y nos sirvieron de enlace) y el propio trabajo etnográfico (personas contactadas en comercios, bares, etc., en cada uno de los contextos).

${ }^{13}$ No hay que olvidar, además del carácter creativo, interpretativo y selectivo que las fotografías implican, la capacidad de la fotografía de dar testimonio de que algo como lo reflejado en ellas estuvo delante del objetivo, estuvo allí, de modo que se atestigua su presencia, posibilitando así un cierto proceso de objetivación, como bien es reflexionado por Barthes en su texto La cámara lúcida (2004). 
materiales obtenidos, pero también a facilitar las comparaciones ad intra o entre casos, tanto a nivel nacional como internacional.

Los equipos de investigación tenían libertad para decidir ofrecer, o no, a todos los entrevistados la posibilidad de realizar la segunda entrevista; algunos países consideraron más apropiado seleccionar entre los hogares entrevistados aquellos más motivados o interesantes desde el punto de vista de la investigación; en otros países, la selección se produjo de forma espontánea por los propios entrevistados (este fue, por ejemplo, el caso de España), ya que se ofreció a todos ellos la posibilidad de realizar la segunda fase de entrevista fotográfica. De cualquier forma, en todos los casos de estudio al menos había ocho entrevistas fotográficas (dieciséis por país). El equipo RESCuE acordó un listado de temas (ver Anexo 2) que se presentó a los entrevistados una vez finalizada la primera entrevista, como ideas inspiradoras respecto de las fotografías a tomar y sobre las que se hablaría en profundidad en una segunda entrevista. El tiempo transcurrido entre la primera y la segunda entrevista se estableció en un intervalo de entre dos y cuatro semanas. Sin embargo, este plazo no fue posible respetarlo en todos los casos (por acontecimientos imprevisibles en la vida de los entrevistados o por decisión del propio equipo investigador ${ }^{14}$. De cada hogar entrevistado se cuenta, por lo menos, con veinticinco fotografías (al menos una por cada concepto propuesto). Como incentivo para la participación en esta segunda entrevista, en algunos países se ofreció como regalo la cámara fotográfica utilizada, en otros, por la propia tipología de los hogares en dificultad, se optó por una tarjeta regalo. Este fue el caso de los hogares en España, en los que el uso de cámaras y móviles está plenamente extendido, y donde la dificultad mayor para las familias más afectadas por la crisis estriba en contar con el dinero necesario para afrontar los gastos comunes. Esta necesidad de adaptación a los contextos nacionales hizo que se dejara abierto el tipo de dispositivo utilizado para realizar las fotografías (móviles, cámaras propias, cámara regaladas en el contexto de la investigación, tabletas, etc.).

Para la preparación de las fotografías, se animó a la participación de todos los miembros del hogar, tanto en la generación de ideas de fotografías para cada tema propuesto y su posterior elaboración o selección, como en las propias entrevistas fotográficas. En el caso español urbano, en varias de ellas participaron finalmente los dos miembros de la pareja; en el caso rural, en ocasiones, han entrado en la dinámica algunos de los hijos de más edad. En Grecia y en Irlanda también se produjo la participación de niños de edades

${ }^{14}$ En el caso español, se intentaba fijar cita para la segunda entrevista a las dos o tres semanas de la primera, si bien en algunos casos fue necesario extender ese tiempo cuando se apreciaba que los participantes no tenían disponibles las fotografías en ese tiempo, con lo que, en ocasiones, se llegó hasta el mes de diferencia entre primera y segunda entrevista. En Alemania, por ejemplo, ese fue el tiempo habitual estipulado entre entrevistas, mientras que en Finlandia dejaron entre cuatro y cinco meses entre ambas entrevistas, precisamente con el objetivo de que hubiera tiempo de fotografiar diversos momentos del año, tan importantes en la vida en el círculo polar, con el inconveniente de extender temporalmente el trabajo de campo. 
inferiores, no siempre con un resultado óptimo.

\section{LA PRODUCCIÓN DE MATERIALES A TRAVÉS DE LA ENTREVISTA FOTOGRÁFICA EN EL PROYECTO RESCUE}

En primer lugar, hay que señalar la enorme potencialidad derivada del hecho de que la entrevista fotográfica sirviera para convocar de nuevo al sujeto entrevistado (o sujetos, ya que varias entrevistas se hicieron a varios miembros de cada familia simultáneamente), habilitando un espacio de ampliación del discurso elaborado por cada una de los hogares. La segunda entrevista, articulada en torno a las fotografías, permitió, no solo ampliar la información obtenida en el primer encuentro, sino profundizar en los aspectos más vinculados a la cotidianeidad de dichos sujetos, aspectos que emergieron con más dificultad en las primeras entrevistas.

En esta segunda entrevista -ahora fotográfica-, se abordaron más temas, contemplándolos más en profundidad, vinculándolos a contextos concretos (su propia casa, el parque que frecuenta, sus lugares de ocio, su barrio-pueblo, sus espacios de interacción cotidiana, sus lugares de trabajo, etc.) y a sujetos concretos (con sus rostros, sus exis corporales, su forma de presentación). Así, la entrevista fotográfica nos sirvió como forma de apoyar una profundización y complementación documental e interpretativa, para apuntalar el proceso de construcción discursiva, pero también para conseguir un acceso privilegiado a espacios y narraciones de la cotidianeidad. Estos espacios permitían reflexionar sobre aspectos que, en muchas ocasiones, los sujetos entrevistados daban por supuesto o a los que no otorgaban especial importancia en su proceso de presentación ante el entrevistador (aspecto destacado por ejemplo por Allen, 2011), brindando un espacio privilegiado para conversar en torno a las estrategias y prácticas cotidianas de supervivencia, de resistencia, de colaboración, de apoyo mutuo, pero también en ocasiones de aislamiento, de vergüenza o de frustración.

Por otra parte, esta oportunidad del segundo encuentro permitió, parcialmente, anclar los discursos en las prácticas cotidianas concretas, de manera que, en muchas ocasiones, una parte importante de las prácticas narradas verbalmente se podían concretar en las imágenes ${ }^{15}$. Sin embargo, en otras ocasiones pudimos ver cómo las imágenes nos abrían líneas interpretativas diferentes e, incluso, a veces, contradictorias, en relación con lo expresado oralmente en la entrevista primera. Por ejemplo, en el caso de UR4 ${ }^{16}$, familia inmigrante peruana, de la primera entrevista se derivaba un cierto aislamiento y

${ }^{15}$ Cómo pescaban en el río como complemento alimentario con imágenes sobre el río en RU6, cómo recogían la leña del bosque para calentar la casa, con imágenes de un entrevistado varón cortando leña en el patio de su casa (en RU2), los juegos infantiles en el parque con imágenes sobre dicho parque próximo al domicilio en UR8, etc.

${ }^{16}$ Como se ve en el anexo 1 hemos denominado UR al caso urbano y RU al rural. El número que acompaña al acrónimo hace referencia al número de entrevista. 
ruptura del capital social como consecuencia de los efectos de la crisis, mientras que en la segunda entrevista pudimos verlos inmersos en todo un rico mundo de relaciones sociales de muy diverso carácter (en la parroquia, en los equipos de futbol, en los grupos juveniles, en las actividades de ocio, en el grupo de los paseantes de perros, etc.) que fueron seleccionadas en numerosas fotografías y que constituyeron objeto de reflexión fundamental en el segundo encuentro ${ }^{17}$.

Además, las fotografías permitieron un acceso privilegiado a una dimensión que, muchas veces, se olvida en los análisis sociales; es la dimensión espacial (especialmente trabajada en sus variantes visuales por Pink, 2008) que queda muy bien registrada en las imágenes. Las dimensiones del hogar, la disponibilidad de espacio, los espacios naturales del ocio, los contextos laborales, las infraestructuras urbanas, las necesidades y recursos para la movilidad, la importancia vital de los viajes, de los desplazamientos a los lugares de trabajo, al encuentro de los familiares,..., quedan plasmados en el registro icónico de la cotidianeidad de los sujetos entrevistados y son desarrollados ampliamente en las narrativas orales que las acompañan. Así, por ejemplo, una fotografía del espacio de trabajo de un trabajador (RU8) que desarrolla su labor dentro de las aspas de los molinos de viento nos transmite una sensación de claustrofobia o agobio que es muy difícil de comunicar verbalmente; una fotografía (UR1) de un patio de un colegio lleno de grietas, rejas oxidadas y tonos grises y apagados, transmite muy bien sensaciones sobre la desigualdad de los recursos educativos, que es muy complicado de comunicar, o siquiera tomar conciencia, verbalmente.

Esta segunda oportunidad de elaborar discurso permitió ahondar en temáticas que fueron poco o nada abordadas en la primera entrevista, indagar en torno a temas que nos generaban desorientación o interpretaciones contradictorias tras una primera aproximación analítica a la entrevista primeramente desarrollada ${ }^{18}$, permitió continuar hablando, ejemplificando, todo ello con el apoyo de unas imágenes de las cuales el sujeto era creador, por lo tanto, especial protagonista $y$, hasta cierto punto, encauzador del proceso dialógico establecido. A pesar de esta capacidad de encauzar el diálogo potenciado por las fotografías, la innegable asimetría de la situación de entrevista no quedó anulada por el hecho de que el objeto que media la conversación fuera construido por el entrevistado. No podemos pasar por alto que las fotografías se elaboran a demanda del equipo investigador, siguiendo el guion temático por el propuesto (aunque solo se propusiera como "ideas inspiradoras"). Este punto de partida, organización e interacción necesariamente conlleva una relación de poder de quien "encarga la tarea" y establece los marcos de su desenvolvimiento. En este sentido, no asumimos la propuesta

${ }^{17}$ Un interesante análisis sobre la relevancia del capital social, la participación y las asociaciones en los procesos de integración de los inmigrantes puede localizarse en el texto de Mireia Bolívar (2011).

${ }^{18} \mathrm{El}$ espacio temporal arbitrado entre la primera y la segunda entrevista posibilitó disponer de un tiempo para hacer una primera aproximación analítica tentativa que pudiera ser rentabilizada en la segunda entrevista fotográfica. 
que, a nuestro modo de ver peca de cierta ingenuidad, de que las entrevistas fotográficas conllevan, por el objeto de su mediación, una interacción más equilibrada y empoderadora por el hecho de dar la voz a los sujetos. Desde nuestra experiencia, hemos podido comprobar que, si bien la relación asimétrica en la situación de entrevista se mantiene, no obstante, el hecho de centrarse la conversación en torno a las fotografías elaboradas, jerarquizadas, ordenadas y seleccionadas por el sujeto entrevistado establece un nuevo contexto en el que las personas cuentan con más recursos para orientar y redirigir la situación dialógica que se establece, fotografías mediante. En este sentido, el diálogo articulado en torno a las imágenes tomadas encuentra un nuevo marco de desenvolvimiento sobre el que el sujeto entrevistado ciertamente tiene un mayor control (en la línea de los trabajos de Harper, 2002). También se ha podido observar cómo en los países y entrevistas o entrevistadores en los que el guion temático se usa de una forma más estructurada y rígida, las relaciones en el seno de la entrevista se orientaban hacia un mayor desequilibrio y jerarquía y el discurso de los sujetos entrevistados se tornaba más escueto y distante (en este sentido, en algunos casos de usos muy rígidos, la dinámica se transformó casi en una situación de muestra de fotografías, vinculación con alguno de los temas del guion y breve comentario en relación a las mismas). Sin embargo, cuando el guion temático se usó de forma flexible y abierta, como muleta para la elaboración del discurso y la narración, se consiguió mayor implicación, discursos más elaborados, reflexivos y, en muchas ocasiones, emotivos.

Al mismo tiempo, hay que señalar que esta ampliación del espacio discursivo, así como este acceso privilegiado a espacios de la cotidianeidad potenciados por las fotografías, se vio desarrollado en una situación de interacción en la cual los sujetos involucrados (entrevistador-investigador y el sujeto entrevistado) ya se conocían a partir de la entrevista previa, con lo cual ya se habían vencido las tensiones, extrañamientos e incomodidades que acostumbran a acompañar los primeros momentos de las entrevistas ${ }^{19}$. Además, el disponer de las fotografías y organizar la conversación en torno a ellas venía a suponer una amplificación del grado de entendimiento, intimidad y confianza que se desplegaba entre ambos sujetos ${ }^{20}$. En todos los casos, la segunda entrevista se desarrolló en un ambiente muy relajado, con un mayor grado de complicidad y confianza que, en buena medida, posibilitó entrar en espacios de la intimidad y la privacidad difícilmente alcanzables en el primer encuentro. Hablar de los próximos, con sus rostros y expresiones, de sus vecinos, de sus frustraciones, de sus conquistas, de los obstáculos y problemas, poniéndolos materialidad, corporeizándolos (icónicamente) y familiarizando la relación, contribuyó a generar una mayor complicidad y emotividad en el desarrollo de

${ }^{19}$ En este sentido la facilitación del primer encuentro, en el contexto de uso de las fotografías teorizada por Meo y Dabenigno (2011) y por Hurworth (2003) no pudo contrastarse, ya que, en esta ocasión, la relación entrevistador-entrevistado ya estaba tejida con anterioridad.

${ }^{20}$ Coincidiendo con la característica ya teorizada por Harper (2002). 
la entrevista ${ }^{21}$. De hecho, en una parte importante de los casos (especialmente en el ámbito rural) las familias nos animaron a volver a visitarlos en cualquier momento, a volver a propiciar el encuentro informal como forma de continuar alargando la relación establecida.

Por otra parte, recordamos que la realización de la entrevista fotográfica tuvo lugar tras un periodo de tiempo en el que la familia entrevistada desarrollaba un proceso de reflexión vinculado al encargo de tomar fotografías de los temas incluidos en el guion (que actuaban como potenciadores de ideas para la selección de las fotografías). Es decir, la segunda entrevista -la fotográficase realizó tras un periodo en el que los temas de la investigación habían sido sometidos a un proceso de reflexión, condensación icónica, ejemplificación y jerarquización. Pensar en tomar fotografías implica un doble proceso: de simbolización metafórica en muchos casos (proceso creativo y metafórico de abstracción), en otros de ejemplificación y concreción desde temas genéricos a contextos concretos, personas, situaciones o escenarios. Este doble proceso conlleva un despliegue reflexivo de los sujetos que se ve acompañado de una interacción interpretativa de dicho proceso en la situación de entrevista, intentando construir el sentido de las imágenes seleccionadas/creadas, junto con el entrevistador en un proceso conversacional (Lapenta, 2004). Se convierte, así, en una dinámica de múltiples y complejas reflexiones, un dispositivo disparador de interpretaciones cruzadas: sobre las intenciones de la investigación, sobre las consecuencias de la entrevista, en torno a los temas propuestos para la reflexión, sobre la creación y selección icónica, sobre la justificación de la selección ante la instancia demandante, sobre las reacciones que dichas interpretaciones provocan en el entrevistador, etc. Esta multiplicación de niveles de interpretación supone un gran enriquecimiento, de cara a cubrir los objetivos de la investigación. Así, por ejemplo, uno de los temas que se proponía en el guion temático de nuestro trabajo de campo era "éxitos y fracasos". Este tema por su especial complejidad y por las dificultades de su concreción material e icónica suscitaba en la entrevista un sinfín de reflexiones, de justificaciones, de interpretaciones en torno a las fotografías seleccionadas que resultaron muy interesantes en el análisis de la resiliencia y la resistencia frente a la crisis ${ }^{22}$.

${ }^{21}$ Coincidiendo con Meo y Dabenigno (2011), la técnica permite fomentar el recuerdo y desplegar la emotividad. Un ejemplo de este proceso en nuestra investigación nos lo proporciona una entrevista (RU4) cuando en ella se comienza a hablar de fotografías del pasado de la familia (llegando a aportar incluso una fotografía de una exhibida en la pared del cuarto de estar); a partir de ella se pudo proceder a abordar la reconstrucción de una biografía caracterizada por la marginación, la lucha política y la represión durante la dictadura de Franco, posicionamiento histórico que ayudó, en buena medida, a comprender la particularidad de las redes sociales tejidas por esta familia en el pequeño municipio y, con ello, su capital social en el enfrentamiento de la crisis.

${ }^{22}$ Por ejemplo, UR7 considera como un éxito de su proceso de enfrentamiento de la crisis el haber sabido innovar en relación con la puesta en marcha de una frutería ecológica (en una construcción discursiva legitimadora de las prácticas de emprendimiento). Ello se pone de relieve en una fotografía de su frutería que entresaca lo más original, lo que diferencia su negocio de otras fruterías convencionales. 
Otro elemento que emergió a partir de nuestra experiencia es el hecho de que, en alguna de las ocasiones, la actividad de sacar fotografías ha estimulado la cooperación de diversas generaciones de la familia, en un proceso en el que los más jóvenes se sienten más capacitados y habilidosos que los más mayores. En alguna de las entrevistas, por ejemplo RU9, uno de los hijos de la familia (con cuatro hijos, padre pequeño empresario) pasa a reflexionar junto con sus progenitores en torno a los temas propuestos y a sugerir fotografías a incorporar; de hecho una parte importante de las mismas fueron realizadas por el propio hijo; lo mismo sucedió en RU6 (familia de cinco miembros, pastores actualmente en situación de desempleo), caso en el que la hija ayudó a realizar una parte de las fotografías que comentaron conjuntamente en la situación de entrevista, al tiempo que alguno de los hijos se incorporaba en la conversación y sugería nuevas ideas para otras fotografías posibles. En términos generales, el hecho de tomar fotografías parece impulsar una mayor colaboración entre los diferentes miembros de la familia en el desarrollo de la situación de entrevista, con lo cual se posibilita una aproximación más holística a la complejidad del hogar (como unidad básica de observación y análisis).

\subsection{Límites y dificultades en el desarrollo de la entrevista fotográfica}

La entrevista fotográfica también introdujo situaciones que implicaron algunas dificultades en el desarrollo de la investigación, así como algunos dilemas éticos. En algunos casos, el requerimiento de la realización de las fotografías disuadió a algunas personas contactadas a involucrarse en la investigación ${ }^{23}$. El temor a no saber desenvolverse con la técnica (con la cámara o el móvil) o el sentimiento auto-atribuido de inferiorización proveniente del escaso conocimiento del lenguaje visual, así como una cierta desconfianza inicial de los posibles usos posteriores de las fotografías, fueron aspectos que, en ocasiones, actuaron como elementos disuasorios de la participación de algunas familias o de una involucración mayor en algún otro caso ${ }^{24}$. De hecho, en cada una de las entrevistas había que explicar detalladamente el funcionamiento de la segunda entrevista fotográfica, con todas las garantías de preservación del

${ }^{23}$ En España, en cuatro de los casos de personas contactadas con las cuales ya prácticamente teníamos acordada la primera entrevista, cuando tuvieron mayor información sobre el proceso y la demanda de la realización de fotografías, así como sobre la segunda entrevista, decidieron no involucrarse en la investigación por rechazo a la participación en esta segunda fase. Por otra parte, en tres de los hogares entrevistados en el caso urbano hubo negativas explícitas a involucrarse en la segunda entrevista fotográfica (ver anexo 1).

${ }^{24}$ Por ejemplo, una de las personas contactadas en España (periodista, en situación de desempleo) se negó a participar por considerar que la parte de las entrevistas fotográficas suponía una especie de "explotación laboral" dada su profesionalidad en el manejo de la fotografía. En Grecia, por ejemplo, algunos sujetos rechazaron participar por su militancia política o por su estatus de inmigrante desprotegido, que les hacía temer que su participación les expusiera ante el público o ante la policía, respectivamente. 
anonimato y con el permiso de publicación exclusiva en la página web del proyecto $^{25}$, con la atribución de autoría cuando así se deseara y, únicamente, para fines investigadores, con la consiguiente firma del consentimiento informado y los compromisos del equipo de investigación.

Solo en algunos casos la idea de la segunda parte de la entrevista potenció el interés por la investigación. Lo que sí se ha mostrado reiteradamente es que, cuando las familias se han involucrado activamente en el proceso de toma de fotografías, se reconoce explícitamente lo estimulante que este proceso ha sido, el divertimento que les ha supuesto, el diálogo familiar que ha fomentado y el disfrute reflexivo que ha suscitado. Esta participación tan estimulante y propiciadora de bienestares ha sido, no obstante, minoritaria. En la mayor parte de los casos la actividad de fotografiar ha supuesto un sobreesfuerzo importante (agotador en algunos casos) en la vida cotidiana de las familias (muchas veces atravesada por una hiperactividad orientada a la consecución de recursos para la supervivencia).

Por otra parte, la entrevista fotográfica implica, en buena medida, una elevada exposición a un extraño, ya que, en ocasiones, el participante se veía invitado a ofrecer más información específica sobre su vida de la que inicialmente podía estar dispuesto a aportar. Por eso en algunos países (Reino Unido, Grecia, Polonia) quedó claro que los entrevistados se sentían más cómodos haciendo fotografías más abstractas o sobre elementos externos a sus vidas y menos comprometidas con las dificultades cotidianas y que, al tiempo, no incluyeran rostros que permitieran la identificación de los sujetos. De esta manera, como señalan nuestros colegas ingleses, los participantes podrían estar utilizando las fotografías como un ejercicio terapéutico, destacando los elementos positivos de su vida ${ }^{26}$.

Otros problemas que se han podido localizar en el desarrollo de estas entrevistas se relacionan con la impericia en el uso técnico de las cámaras que ha obligado en algunas ocasiones a contar con la ayuda de familiares jóvenes; a ello hay que añadir el diferente grado de alfabetización visual de los sujetos, de modo que, en algunas ocasiones y para algunos sujetos, resultaba tremendamente complicado pensar en imágenes y, en otras, se explicitaba la gran complejidad implicada en la actividad, especialmente en relación con los temas más abstractos.

En este sentido, la mayoría de los participantes siguieron solo parcialmente el guion de temas propuestos aportando fotografías para todos ellos; en muchas ocasiones, simplemente prepararon ideas y fotografías para algunos de los ítems, con los que se sentían más cómodos y capaces de convertir en imágenes. Las

${ }^{25}$ Las fotografías resultantes del proceso, de las cuales contamos con el consentimiento informado de publicación, serán subidas a la página web: www.rescueproject.eu a finales de 2016.

${ }^{26}$ Por supuesto, se insistió repetidamente en que las personas cedieran las fotografías que ellos desearan aportar a la investigación y con las que se sintieran cómodos. 
razones alegadas para no completar el conjunto de la demanda tenían que ver, a veces, con la dificultad para comprender la tarea, o para encontrar inspiración sobre la conversión de palabras, sentimientos o ideas en imágenes, mientras que en otras ocasiones y contextos se aludía a lo alejados que estaban los ítems de su forma habitual de fotografiar. Muchos participantes expresaban sus dudas sobre qué es lo que debían fotografiar, incluso solicitando indicaciones al entrevistador. Aun así, en algunos casos (Alemania) se decidió tomar las fotografías junto con el entrevistado, preguntando qué quería fotografiar y a qué tema correspondería. Otra forma de enfrentar esta dificultad consistía en retrasar la segunda entrevista, dando más días a la preparación de las fotos, al tiempo que se explicaba nuevamente la demanda del equipo investigador para mayor claridad (Finlandia, Portugal), incluso aportando ejemplos extraídos de la primera entrevista con la persona (Irlanda). En Irlanda las investigadoras utilizaron la guía como una herramienta para co-construir la relación entre la imagen y alguno de los ítems temáticos, algo que también sucedió con algunos entrevistados españoles.

En algunos casos, los entrevistados decidieron traer al encuentro fotografías ya existentes, no tomadas expresamente para la investigación, de las que podían disponer en tarjetas de memoria o en sus propias redes sociales (en Facebook, por ejemplo), como en Grecia y en España. En otros casos, los participantes proporcionaron algunas imágenes que no trataron de relacionar con los temas propuestos. En alguna ocasión, simplemente, mostraban al entrevistador imágenes digitales disponibles en algún dispositivo y le daban permiso para su uso. Entendemos que el hecho de tomar fotografías ya existentes no supone una dificultad para la investigación, en la medida en que los participantes establecieran el vínculo con alguno de los temas propuestos. Al fin y al cabo, hay muchas experiencias de la vida de los entrevistados (todo lo que tiene que ver con el pasado o con acontecimientos que tienen lugar en determinadas épocas del año) que eran imposibles de fotografiar en el tiempo de que disponían para realizar las fotografías. En muchas ocasiones, este uso de meta-referencias contribuyó a ahorrar esfuerzos o a sustituir la realización de fotografías que implicaban alguna dificultad ${ }^{27}$.

En conjunto, da la impresión de que, aunque se dice que nuestra sociedad es más visual que nunca y que las personas toman más fotografías que nunca en la

${ }^{27}$ Por ejemplo, en un caso de una entrevista a una familia inmigrante (UR1), la mujer, al hablar de "su futuro" extrae de la web una fotografía de una peluquería y señala que su ilusión sería ahorrar para poder poner en su país de origen una peluquería. Pensamos que este uso metareferencial evita la exposición de la mujer a una situación desagradable de entrar en un local a hacer una fotografía, al tiempo que le permite ahorrar esfuerzos. En otro caso (RU4), la familia toma una fotografía de un retrato exhibido en la pared de su salón. A pesar de ser una fotografía metareferencial, adquiere un valor simbólico fundamental en tanto recoge algo crucial en la narración biográfica de la familia, pero que es imposible fotografiar en la actualidad (familia extensa con miembros ya fallecidos) y recoge un elemento clave en la vida familiar que es exhibida en su espacio íntimo. Se puede consultar en este sentido las interesantes reflexiones de Bourdieu \& Bourdieu (2010) sobre los usos de las fotografías familiares. 
historia, muchos de nuestros participantes (de manera más notoria la población de mayor edad), en cada uno de los nueve países, no están acostumbrados a explicar conceptos con imágenes auto-referidas o, en general, a manejarse con lenguajes visuales.

\section{EL PROCESO DE ANÁLISIS EN EL USO DE LA ENTREVISTA FOTOGRÁFICA}

En primer lugar, hay que señalar que encontramos un problema vinculado al análisis, que se relaciona con la gestión por parte del equipo de investigación de las propias fotografías: cómo organizarlas, cómo adscribirlas a los textos transcritos de la entrevista, cómo conseguir la máxima calidad. Estas son cuestiones que obligaron a buscar formas flexibles de recogida, así como a desarrollar un riguroso sistema organizado de denominación e identificación de cada una de las fotografías, adscribiéndolas a su autor/a, ubicándolas en su relación con el discurso oral en torno a las mismas, de manera que se facilitara su localización en el momento de su referencia en la entrevista (procurábamos referirnos explícitamente a algún aspecto de la imagen para posteriormente poder ubicarla junto con la transcripción del discurso oral).

Además de esta cuestión vinculada a la gestión de los materiales para posibilitar su análisis, una reflexión interesante en el uso de este dispositivo se relaciona con el hecho de permitir apoyar con otro tipo de lenguaje -icónicolos puntos de vista, las perspectivas y cosmovisiones de los sujetos que fueron entrevistados; es decir, al contar simultáneamente con varios tipos de lenguaje (verbal e icónico en este caso), en un proceso multimodal, se multiplican los indicios conducentes a interpretaciones posibles del sentido de los discursos y posiciones. De esta forma, al mismo tiempo, se facilita el proceso de interpretación, gracias al efecto multiplicador de los indicios susceptibles de interpretación, al tiempo que se contribuye a generar redundancia y saturación que puede favorecer el hecho de ir tomando seguridad en las interpretaciones y conjeturas. Hablar implica posicionamiento del sujeto, pero también tomar fotografías y seleccionarlas lo implica, con lo cual se multiplican las vías de acceso a las perspectivas, las vivencias y las cosmovisiones ${ }^{28}$.

Además del proceso hiper-reflexivo previamente comentado que se fomenta en el sujeto entrevistado, el dispositivo permite proveer de espacios reflexivos para el entrevistador sobre los propios procesos de interacción en los que dicho proceso comunicativo se inserta, sobre la interacción entre entrevistador y entrevistado, sobre la situación de entrevista y sobre la comprobación de

\footnotetext{
${ }^{28}$ Por ejemplo, en UR1 a partir de la entrevista oral se pudo derivar una situación social de inserción social muy precaria y de aislamiento. De la misma manera, en las fotografías no aparecen, en ningún momento, personas, ni familiares, ni situaciones sociales, ni siquiera en los temas centrados en las relaciones sociales; en RU5 interpretaciones sobre posiciones de liderazgo de un varón en grupos de pertenencia, se vieron reforzados por fotografías en las que el sujeto aparece en posición de centralidad en el seno de actividades grupales o de celebraciones rituales.
} 
cómo la entrevista es una situación de co-producción (en la línea del trabajo desarrollado por Jenkings et al., 2008) en la lectura e interpretación de las fotografías que se inicia en el mismo momento del desarrollo de la segunda entrevista. Como se ha señalado previamente, en muchas ocasiones se aportan fotografías que no se vinculan a ninguno de los epígrafes del guion, en otras muchas, se duda en relación a los temas a los que asignarlos, en otros casos se pide al entrevistador colaboración en el proceso. En estas situaciones, generalmente, se introduce un diálogo entre el entrevistador y el entrevistado en el proceso de "etiquetaje" que deviene en una forma de proto-análisis coconstruido entre el investigador (entrevistador) y el entrevistado.

Por otra parte, vinculándolo al potencial de registro de información que se deriva del carácter documental (limitado) de las fotografías, hay que señalar que disponer para el análisis, de fotografías de los micro-contextos en los que se ubican los sujetos entrevistados contribuye a familiarizarnos más con ellos (mayor introspección empática en términos de Kohut, 2009), a recordarlos cuando con el paso de un tiempo se vuelve sobre ellos, a revivir la situación de entrevista, a abrir la posibilidad de una cierta inmersión (parcial y limitada) de otros miembros del equipo que no han estado presentes en el contexto de la situación de interacción. De esta manera, como las entrevistas fueron realizadas por un solo entrevistador (exceptuando algún caso aislado de entrevistas que se desarrollaron por parte de dos entrevistadores), mientras que el equipo de investigación es muy numeroso (cinco miembros en España y treinta y dos si contamos los investigadores de los nueve países implicados), la materialidad de las fotografías posibilitó un acceso a los hogares más próximo, personal y empático a aquellos miembros del equipo de investigación no presentes, que si el análisis se hubiera basado exclusivamente en el discurso oral.

Además, el registro fotográfico de los micro-contextos, seleccionados y preinterpretados por los propios protagonistas permite un acceso lento, pausado, parsimonioso y compartido de diferentes investigadores a los contextos a analizar y a sus materializaciones icónicas. No es lo mismo la observación fugaz, apresurada y relativamente tensionada del hogar o del barrio o del rostro de los acompañantes, que se produce en el contexto de la realización de la entrevista, que la posibilidad de mirar lentamente cada uno de los detalles que conforman las fotografías (las grietas de las paredes, la expresión del rostro, la exis corporal, la forma trabajada de las manos, los elementos decorativos del hogar, por poner algunos ejemplos). Además, la posibilidad de mirar simultáneamente varios investigadores, intercambiando interpretaciones sobre un mismo material, ofrece enriquecimiento y la posibilidad de triangular puntos de vista e ir tomando seguridad en las interpretaciones.

Por otra parte, retomando el carácter internacional de la investigación que se comenta conviene señalar que la producción de material icónico en las entrevistas fotográficas, al compartir un lenguaje icónico no tan pegado a las culturas y a las naciones, ha posibilitado desplegar procesos analíticos de carácter internacional, sin necesidad de recurrir a la traducción linguística de cada una de las transcripciones de entrevistas. Así, se ha posibilitado el 
desarrollo de encuentros comparativos de las fotografías construidas por los hogares seleccionados ${ }^{29}$. Es, entonces, esta mayor facilidad para establecer comparaciones de carácter internacional otra de las potencialidades vinculadas a la técnica de la entrevista fotográfica.

\section{DIVERSIDADES Y DIVERGENCIAS EN EL PROCESO DE TOMA DE LAS FOTOGRAFÍAS}

Además de las diferencias en la dinámica de la entrevista fotográfica que ya se han ido comentando, el uso de la técnica ha tenido desarrollos muy diversos en las variadas situaciones generadas en nuestra investigación; encontramos variabilidad en relación con los temas (sujetos, objetos, escenarios, contextos) seleccionados prioritariamente en las fotografías, en la propia presencia y protagonismo de la familia en las imágenes, en el grado de pericia tecnológica e icónica desplegada por los sujetos entrevistados, en el grado de competencia comunicativa (Hymes, 1972; Cenoz, 1996) visual, en la implicación, compromiso y disfrute -o rechazo- en la realización de las fotografías, en el recurso hipertextual a otras fotografías -o textos- de la mediasfera, en la capacidad de simbolizar y/o metaforizar icónicamente, en la posibilidad de traducir o relacionar lenguajes (icónico y verbal), así como en la capacidad para interpretar imágenes. Podemos, así, señalar, coincidiendo con Lapenta (2004), que existe un diferente grado de "alfabetización icónica", que Lapenta interpreta como proveniente de diferentes socializaciones visuales (2004: 207). Conviene, en este sentido, retomar las reflexiones de Bourdieu (1965) en torno a la fotografía como praxis estructurada. Para este autor, la fotografía expresa, además de las intenciones explícitas de quienes las han hecho, el sistema de esquemas de percepción, pensamiento y apreciación común al grupo de pertenencia (1965:24). Cada grupo hace una selección de posibles temas, momentos, composiciones que fotografiar, hecho que incide en el carácter normativo de la práctica fotográfica analizada por este autor y que se relaciona con las jerarquías y los grupos sociales, así como con sus representaciones.

En este sentido, centrándonos, por ejemplo, en el caso español, se ha podido comprobar que existen importantes diferencias etarias en el desarrollo de las entrevistas fotográficas, de forma que los más jóvenes se encuentran mucho más cómodos sacando fotografías, ya que esta actividad se inserta en formas de interacción cotidiana naturalizadas por ellos, los cuales se presentan en forma de imágenes, interaccionan compartiendo imágenes, al tiempo que constantemente son interpelados como consumidores visuales (Reguillo Cruz, 2000). De esta forma, se implican y disfrutan más en la actividad. Los más mayores, menos familiarizados con el lenguaje visual, se encuentran más distantes e, incluso,

${ }^{29} \mathrm{El}$ principal encuentro centrado en el análisis visual comparativo de las fotografías se celebró en Madrid en el mes de marzo de 2015 en una reunión conjunta del equipo internacional de investigación. 
se resisten más a la actividad, muestran mayor impericia, piden ayuda técnica a familiares jóvenes, pero también piden colaboración con ideas para la toma de las fotografías.

Otra de las dimensiones en torno a las cuales encontramos una importante diversidad en el uso de la técnica es la que tiene que ver con el hábitat. En nuestro caso urbano, encontramos, globalmente, una menor implicación y compromiso con la actividad fotográfica, de manera que, en términos generales, las familias sacan menos fotos, éstas están menos argumentadas, reflexionadas $\mathrm{u}$ organizadas, al tiempo que el detenimiento en el relato de las seleccionadas es más infrecuente. Simultáneamente, encontramos más casos en los que hay una actitud de cierta desconfianza hacia la actividad de la toma de fotografías relacionadas con su cotidianeidad, al tiempo que, en el aspecto de contenido temático, hay una predominancia de temas, contextos y escenarios relacionados con el propio hogar, la casa y el ámbito privado. Sin embargo, en nuestro caso rural aparecen mucho más frecuentemente escenarios exteriores al hogar, así como actividades laborales (relacionadas con actividades agrícolas, ganaderas, artesanales, pero también industriales), vinculadas a los "bienes comunes" (la recogida y uso de leña, por ejemplo), con los rituales de potenciación del sentido de comunidad (reuniones de amigos, cofradías, festividades religiosas, comidas campestres) y una presencia fuerte de la familia extensa y sus cotidianeidades. Estas diferencias en el desarrollo de la dinámica del dispositivo pueden, en buena medida, relacionarse con una cierta diversidad en la organización de las temporalidades en las fracciones más desfavorecidas de las clases populares en ambos contextos, de manera que en el caso urbano, en mayor medida, sus ritmos tienden a organizarse más en torno a las necesidades de supervivencia inmediatas, imponiendo también "temporalidades arrítmicas" (Millet y Thin, 2005: 158) distantes de la temporalidad cronométrica que impone el espacio del trabajo, de la educación, de los espacios ritualizados de la religión o la familia. En tiempos y lugares dominados por el imperativo de la inmediatez y el presente, $\mathrm{o}$, a veces, las angustiosas esperas de prestaciones, en las colas de los servicios sociales o asistenciales, etc., el encargo de planificar una serie de fotografías vinculadas a un guion que reviste una cierta complejidad, organización y previsión de la tarea, va acompañado de una necesaria asincronía. En nuestro caso, ciertamente los sectores urbanos, pero también, en general, aquellos más desfavorecidos de nuestra muestra, aquellos en condiciones más precarias, no organizaron la toma de fotografías de una manera sistemática y tuvieron un grado muy inferior de compromiso con la tarea. También, en relación con las diversidades en capital cultural (Bourdieu, 1998), encontramos que cuanto mayor es éste en las familias, se puede localizar una mayor implicación en la toma de las fotografías, mayor organización, reflexión en torno a ellas en el espacio de la narración oral, así como una mayor presencia del uso simbólico y metafórico de las imágenes. Como señalan Curry y Strauss (1994) y Bender et al. (2001), los contenidos simbólicos suelen exigir un análisis más pormenorizado de los elementos reunidos en la fotografía y este es un proceso que requiere una cierta capacitación o alfabetización visual. Así, como se ha 
podido comprobar en nuestro trabajo de campo, no todos los grupos están en disposición de poder proceder a esta condensación metafórica.

También se observan discrepancias en relación a los usos de las fotografías por parte de inmigrantes y población autóctona. En el grupo de inmigrantes presentes en nuestra investigación, en ambos contextos, rural y urbano, encontramos familias que muestran un mayor rechazo a su representación en las fotografías (por ejemplo, UR1, familia ecuatoriana, con un fuerte proceso de asunción vergonzante de su afectación por la crisis), otros que directamente rechazan su posible aparición (como es el caso de UR8, familia marroquí para la cual hay un rechazo cultural a ciertos usos de las fotografías de los sujetos). En otros, sin embargo, se remarca su integración exitosa en la comunidad a través de la multiplicación de imágenes de sus espacios de sociabilidad próxima (es el caso por ejemplo de UR4, familia peruana, o de RU12, joven rumana, ambos casos con fuerte integración comunitaria).

La dimensión de género también nos permite observar unas ciertas regularidades, de forma que los varones tienden a asumir con mayor implicación el encargo de la realización de las fotografías (con mayor dedicación y organización), al tiempo que las mujeres usan la toma de las imágenes desde una posición más espontánea, más improvisada, más recurrente a fotos el pasado o fotografías de otras fotos (con meta-referencias a otros textos icónicos que son reproducidos miméticamente). En relación con el contenido de dichas fotografías, son los espacios del hogar y la familia los más presentes en el caso de las mujeres, mientras que son los espacios laborales y de socialización amplia los más presentes en el caso de los varones.

\section{EL ARCHIVO DE IMÁGENES Y LAS BASES DE DATOS CUALITATIVAS}

Además de las potencialidades y limitaciones de la entrevista fotográfica vistas anteriormente, existen otras razones que justifican el interés por esta técnica. En comparación con las fuentes de datos cuantitativos, el aprovechamiento de la investigación cualitativa como fuente secundaria de información tiene limitaciones importantes. La singularidad de la aplicación práctica de las técnicas cualitativas, incluidos los análisis producidos, genera algunos inconvenientes a la hora de aprovechar dicha información por terceros, especialmente para su utilización desde un punto vista comparativo a nivel transcultural. La complejidad de la información cualitativa requiere a su vez una cantidad no mucho menor de meta-información adicional para su reutilización y aprovechamiento. Se trata en definitiva de información reutilizable de forma limitada debido al problema de la estandarización de referentes comunes a partir de los cuales el material producido es interpretado. Es por este motivo que los bancos de información cualitativa procedentes de la investigación social 
se han visto relegados muchas veces a fondos 'museísticos' infrautilizados ${ }^{30}$. Ahora bien, atendiendo a las aportaciones de la entrevista fotográfica que se han derivado de la investigación que se presenta en este artículo, esta dificultad debe matizarse. La inclusión de la imagen visual, producto de las entrevistas realizadas con el método de la foto-elicitación en distintos países, culturas y grupos sociales, nos aporta algunos avances sobre el problema que se plantea; sobre todo pone de relieve que la imagen contribuye, en diverso grado, a hacer más accesible, comparable y reutilizable parte de la información producida en la investigación cualitativa.

Desde un punto de vista técnico, el aparato fotográfico trae consigo marcos referenciales que favorecen la investigación comparada y la posibilidad de producir y registrar información cualitativa más accesible y reutilizable. En primer lugar, la cámara impone al informante y al investigador una especie de "programa" que estandariza una parte importante de la observación (Flusser, 1990). En segundo lugar, dicho programa permite registros de la realidad en un formato y lenguaje reconocible a pesar de los códigos culturales (y grupales) implícitos, tanto en la manipulación del aparato, como en el material registrado/ construido. En este sentido, las fotografías, a pesar de ser culturalmente construidas, se producen sobre una serie de referentes comunes (el aparato técnico -con sus potencialidades y limitaciones- y la similaridad icónica con el referente ${ }^{31}$ ). En este sentido, Barthes (1989) hace referencia a cómo, en las imágenes fotográficas, el referente se incorpora a la representación más que en otros tipos de imaginería y señala cómo, a pesar de que la fotografía enmarca, selecciona y construye realidad, en ella siempre queda algo de lo que estuvo delante de la cámara cuando se disparó.

En este sentido, la cámara fotográfica permite operar una primera estandarización de los datos secundarios cualitativos ${ }^{32}$, aunque esta primera estandarización no es suficiente para garantizar la reutilización de las imágenes en la investigación. Cuanta más información podamos aportar en relación con el contexto de producción de las fotografías, en mejor disposición se estará para poder hacer una interpretación de las mismas. Es por ello que, en el caso de la entrevista fotográfica, el hecho de poder disponer de las fotografías, junto con un texto oral en el que se da cuenta de las mismas, se contextualizan y se interpretan

${ }^{30}$ En los últimos años se está tratando de revertir esta situación promocionando los archivos cualitativos. Para ello se ha creado la Red Europea de Archivos Cualitativos (EQUALAN). En algunos países de nuestro entorno, como Inglaterra, Irlanda, Finlandia y Alemania, ya cuentan con una red de archivos cualitativos que se ha ido consolidando en los últimos años.

${ }^{31}$ Remitimos, en este sentido, a la clásica concepción de "icono" como una de las formas en las que Peirce (2012) clasifica los signos. Para este autor el "icono" mantendría una relación directa de semejanza con el objeto, en tanto se parece a él (y uno de los ejemplos típicos de estos iconos, son precisamente las fotografías).

${ }^{32}$ Más que conseguir un lenguaje común (a los diversos grupos, culturas y temporalidades) como apuntan Ziller (1990) o Douglas (1998), lo que permite la imagen fotográfica es una primera estandarización de los procedimientos expresivos de los sujetos entrevistados, primera estandarización que facilita tanto la comparación internacional como el uso secundario de dichos materiales. 
a la luz de una situación dialógica (entre entrevistador/a y entrevistado/a) permite acceder a las imágenes con mayores posibilidades de reconstruir, aunque solo sea de forma parcial, su contexto de producción. Para ello será importante incluir también en el archivo, las referencias contextualizadoras aportadas por el equipo de investigación, que permitan ubicar socio-estructuralmente cada una de las imágenes susceptibles de formar parte del archivo.

En este sentido, la imagen (y, más aún, la multimodalidad que posibilita la combinación del discurso oral y el visual en la entrevista fotográfica) ofrece una economía de posibilidades que no ofrece el discurso verbal o el texto escrito aislado. La imagen ofrece la posibilidad de establecer registros concretos relativamente estandarizados sobre los elementos que son, a su vez, registrados por la máquina óptica y seleccionados y pre-textualizados por el creador de dichas imágenes. Es por este motivo que la imagen se muestra apropiada para la construcción de fuentes secundarias cualitativas; porque la información discursiva (verbal o escrita) encuentra un valioso soporte de registro, relativamente estandarizado, que ayuda a interpretar su significado. En este doble sentido se podría decir que el registro fotográfico es enriquecedor para una labor interpretativa, siempre que se entiendan como imágenes que han sido producidas y distribuidas por medio de aparatos automáticos y programados que enmarcan tanto la libertad codificadora del sujeto social cuando observa el mundo, como su intento por descodificarlo.

\section{CONCLUSIONES}

La entrevista fotográfica cuenta ya con una dilatada experiencia y un acervo importante de trabajo empírico que reflexiona sobre sus potencialidades y prácticas. Como se muestra en el artículo, esta técnica, inserta en el conjunto de las metodologías visuales, se ha desarrollado fundamentalmente en el contexto anglosajón, siendo mucho menor la difusión de esta técnica en España. Un ejemplo lo constituye esta investigación internacional desarrollada en el marco del proyecto RESCuE. En él se utiliza material visual a través del uso de (segundas) entrevistas fotográficas junto a otras técnicas cualitativas de producción de información (entrevistas abierta a informantes clave y hogares y observación etnográfica). A lo largo del artículo ha quedado justificada la productividad de esta técnica, pero también se han señalado algunas cuestiones a tener en cuenta cuando se incorpora en un diseño de investigación concreto.

Entre las potencialidades o riqueza que aporta a la investigación realizada, se constatan muchas de las ya apuntadas por otros autores, y que, en este caso, han permitido una profundización, y complementación informativa y temática, en torno a las estrategias y prácticas para salir adelante de las familias afectadas por la crisis. Por un lado, ha permitido anclar los discursos en las prácticas cotidianas concretas, acceso privilegiado a espacios de la cotidianeidad que de otra manera estarían vetados o que no suelen aparecer espontáneamente al ser dados por supuesto o no otorgarles importancia, pero que resultan claves para entender las 
prácticas cotidianas de supervivencia, de resistencia, de colaboración, de apoyo mutuo, y también de aislamiento, de vergüenza o de frustración. Ha permitido matizar el discurso (las imágenes abren a veces líneas interpretativas diferentes, e incluso contradictorias en relación con lo expresado oralmente en la entrevista primera), mayor implicación de los entrevistados (la relación asimétrica de entrevista puede compensarse con dinámicas más flexibles que el uso de imágenes permite), una mayor cercanía a los entrevistados o dar mayor solidez a las interpretaciones y conjeturas en el análisis al verse apoyadas de manera redundante tanto en el lenguaje oral, como en el icónico.

Por otro lado, que la información esté registrada a través de imágenes tiene ventajas añadidas relevantes para los investigadores. Además de posibilitar una mayor familiaridad con los entrevistados, facilitar el recuerdo o compartir el material y las interpretaciones entre los miembros del equipo de investigación de manera más sencilla, hay que destacar que la imagen se muestra doblemente apropiada para la construcción de fuentes secundarias cualitativas, porque la información discursiva (verbal o escrita) encuentra un valioso soporte de registro parcialmente estandarizado que esclarece tanto su significado, como el de los elementos que intervienen en la estructura de la información visual.

No obstante, la utilización de la entrevista fotográfica en el proyecto RESCuE no está exenta de inconvenientes, derivados unas veces de la propia técnica, y otras de cómo se ha diseñado su utilización y puesta en práctica en los distintos países. Por ejemplo, la cuestión ética vinculada al uso de imágenes y su posible difusión continúa sin tener una respuesta satisfactoria. Aunque se garantice el anonimato y se recaben consentimientos firmados que recojan el compromiso de ambas partes, no es infrecuente la presencia de quienes desisten de participar por la desconfianza que les genera. Por otro lado, la tarea de realizar fotografías puede resultar estresante para los entrevistados, bien por estar ocupados con las exigencias del día a día, o por las dificultades técnicas derivadas del uso de cámaras o móviles, o de la grabación y organización de las imágenes, pero también por la complejidad de la tarea solicitada. Algunos temas propuestos resultan demasiado abstractos o excesivamente conceptuales, a la par que demandan gran cantidad de tiempo a los entrevistados y pueden resultar en ocasiones intrusivos (elevada exposición ante extraños).

\section{BIBLIOGRAFÍA}

ALLEN, Q. (2012). "Photographs and stories: ethics, benefits and dilemmas of using participant photography with black middle-class male youth", Qualitative Research August 2012, 12, 443-458.

ALLEN, L. (2011). "Picture this': using photo-methods in research on sexualities and schooling" Qualitative Research, October, 2011, 11, 487-504

ARIAS, D. (2011). "El co-relato de la imagen fotográfica: la arqueología visual como metodología en la exploración de la memoria etnohistórica”, QuAderns-e N No 16 (12), 2011 pp. 173-188

BANKS, M. (2008). Using visual data in Qualitative Research. London, Sage. 
BANKS, M. (2001). Visual Methods of Social Research. London, Sage

BARLOW, C.A. \& HURLOCK, D. (2013). "Group meeting dynamics in a communitybased participatory research Photovoice Project with exited sex trade workers", International Journal of Qualitative Methods 2013, 12, 132-151.

BARTHES, R. (2004). La cámara lúcida. Nota sobre la fotografía. Barcelona, Paidós Comunicación

BENDER, D. E. et al. (2001). "Tell me what you mean by 'si': Perceptions of quality of prenatal care among immigrant latina women”. Qualitative Health Research, 11, 6, 780-794.

BOLIVAR, M (2011). "Las asociaciones en las redes personales ¿Mecanismo de integración de la inmigración?" REDES-Revista hispana para el análisis de redes sociales, vol. 20, \#7, junio 2011 [http://revista-redes.rediris.es].

BOLTON, A., POLE, C. y MIZEN, P. (2001). "Picture this: researching child workers", Sociology, 35 (2), 501-518

BOURDIEU, P. (1965) (Dir) Un art moyen. Essai sur les usages sociaux de la photographie. Paris, Minuit

BOURDIEU, P. (1998). La distinción: criterios y bases sociales del gusto. Madrid, Taurus Ediciones.

BOURDIEU, P. y BOURDIEU, M.C. (2010) "El campesino y la fotografía" En P. BOURDIEU El sentido social del gusto. Elementos para una sociología de la cultura. Buenos Aires, Siglo XXI

BRIDGER, L. (2013). "Seeing and telling households: A case for photo elicitation and graphic elicitation in qualitative research", Graduate Journal of Social Science May 2013, Vol. 10, Issue 2, 106-131

CAMPOS, J. M., \& DOLLINGER, M. (1998). “An autophotographic study of poverty, collective orientation, and identity among street children", The Journal of Social Psycology, 138(3), 403-406

CENOZ, J. (1996). "La competencia comunicativa: su origen y components", en J. Cenoz. y J. Valencia (eds.). La competencia pragmática: elementos lingüísticos y psicosociales. Leioa, Universidad del País Vasco, 95-114.

CLARK-IBÁÑEZ, M. (2004). "Framing the social world with photo-elicitation interviews". American Behavioral Scientist (ABS). August, 2004, vol. 47, no. 12, 1507-1527.

COLLIER, J. \& COLLIER, M. (1986). Visual Anthropology. Albuquerque. University of New Mexico Press.

CORONEL, J. M. \& RODRIGUEZ, I. (2013). "Let me put it another way: methodological considerations on the use of participatory photography based on an experiment with teenagers in secondary schools". Qualitative research in education. 2013, 2 (2), 98-129.

CREIGHTON, G.M.; BRUSSONI, M., OLIFFE, J.L. \& HAN, C. (2015). "Picturing masculinities: using photo-elicitation in men's health research". American Journal of Mens Health. October 18, 2015.

CURRY, T.J. \& STRAUSS, R.H. (1994) “A little pain never hurt anybody: a photoessay on the normalization of sport injuries". Sociology of Sport Journal, 11, 2, 195-208.

DAVILA LEGUERÉN,A. (2015). “A la luz de la propia sombra. Incorporaciones de la fotografía a la sociología" Fotocinema. Revista científica de cine y fotografía, $\mathrm{n}^{\circ} 10$ (2015), 285-326 
DOUGLAS, K. B. (1998). "Impressions: african american first-year students' perceptions of a predominantly white university". Journal of Negro Education, 67, 4, 416-431.

EPSTEIN, I., STEVENS, B., MCKEEVER, P., \& BARUCHEL,S. (2006). "Photo elicitation interview (pei): using photos to elicit children's perspectives", International Journal of Qualitative Methods 5 (3) September 200. http://www. ualberta.ca/ iiqm/backissues/5_3/pdf/ epstein.pdf [fecha de consulta 15-6-2016]

ESCALANTE, G. (2015). "Photovoice: voces sin sonido" en Servicios sociales y política social, $\mathrm{n}^{\circ} 109,151-162$.

EVANS-AGNEW, R.A. \& ROSEMBER, M.S. (2016). "Questioning photovoice research: whose voice?" Qualitative Health Research, Vol. 26(8), 1019-1030.

EWALD, W. \& LIGHTFOOT, A. (2005). I wanna take me a picture: teaching photography and writing to children. Boston, Beacon Press, 2005

FLUSSER, V. (1990). Hacia una filosofía de la fotografía. Mexico D.F, Trillas.

GALLMAN, S. (2009). "The truthful messenger: visual methods and representation in qualitative research in education", Qualitative Research, 9, 197-217.

GIBSON, B.A., MISTRY, B., SMITH, B., YOSHIDA, K.K., ABBOTT, D., LINDSAY,S. \& HAMDANI,Y. (2013) "The integrated use of audio diaries, photography and interviewa in research with disabled young men" International Journal of Qualitative Methods, 2013, 12, 383-402.

HARPER, D. (2002). "Talking about pictures: a case for photo elicitation", Visual Studies, 17(1), 13-26.

HARPER,D. \& FACCIOLI, P. (2010). The italian way. Food and social life. Chicago, University of Chicago Press

HAZEL, N. (1995). "Elicitation techniques with young people", Social Research Update (12). http://www.soc.surrey.ac.uk/sru/SRU12.html. [fecha de consulta 25-5-2016]

HEISLEY, D. D. \& LEVY, S. J. (1991). "Autodriving a photoelicitation technique". Journal of Consumer Research, 18, 257-272.

HURWORTH, R. (2003). "Photo-Interviewing for research", Social Research Update (40). http://www.soc.surrey.ac.uk/sru/SRU40.html. [fecha de consulta 22-5-2016]

HYMES, D. (1972). "On communicative competence", en J. B. Pride y J. Holmes (eds.), Sociolinguistics. Harmondsworth: Penguin, 269-285.

JOANOU, J. (2009) “The bad and the ugly: ethical concerns in participatory photographic methods with children living and working on the streets of Lima, Perú" Visual Studies. 2009, 24 (3), 214-233

JENKINGS, K.N., WOODWARD,R. \& WINTER, T. (2008) “ The emergent production of analysis in photo elicitation: pictures of military identity", FQS, Forum: Qualitative Social Research, $\mathrm{Vol} 9, \mathrm{~N}^{\circ} 3$, art 30.

KAPLAN, I., LEWIS, I. y MUMBA, P. (2007), "Picturing global educational inclusion? Looking and thinking across students photographs from the UK, Zambia and Indonesia", Journal of Research in Special Educational Needs, 7(1): 23-35.

KOHUT, H (2009) "Introspección, empatía y psicoanálisis. Un examen de la relación entre el modo de observación y la teoría" en Revista de Psicoanálisis, LXVI, 1, 2009, págs. 17-40

KOLB, B. (2008) "Involving, sharing, analysing: Potential of the participatory photo interview” FQS, 2008, 9 (3) Art. 12. http://nbnresolving.de/urn:nbn:de:0114fqs0803127 [fecha de consulta 18-5-2016] 
LAPENTA, F. (2004). The image as a form of Sociological data: a methodological approach to the analysis of photo elicited interviews. Thesis presented for the degree of $\mathrm{PhD}$ (sociology). Goldsmiths College: University of London

LUNA HERNÁNDEZ, J.R. (2009). "Foto-etnografía llevada a cabo por personas en situación de pobreza en la frontera norte de México", FQS, Forum: Qualitative Social Research, 10 (2) Art 35.

LYKES, M., BLANCHE, M., \& HAMBER, B. (2002) Narrating survival and change in Guatemala and South Africa: The politics of representation an a liberatory community psychology. American Journal of Community Psychology, 2002, 31 $(1 / 2), 79-90$.

MANNAY, D. (2013). "Who put that on there ... why why why? Power games and participatory techniques of visual data production", Visual Studies, 2013, Vol. 28, No. 2, 136-146

MEO, A. y DABENIGNO, V. (2011) "Imágenes que revelan sentidos: ventajas y desventajas de la entrevista de foto-elucidación en un estudio sobre jóvenes y escuela media en la Ciudad de Buenos Aires", EMPIRIA. Revista de Metodología de Ciencias Sociales. N.o 22, julio-diciembre, 2011, pp. 13-42

MILLER, K. (2014). "Learning about children's school preparation through photographs: The use of photo elicitation interviews with low-income families", Journal of Early Childhood Research. Dic. 17, 2014

MILLET, M. Y THIN, D. (2005). "Le temps des familles populaires à l'épreuve de la précarité" Lien social et Politiques, $\mathrm{n}^{\circ}$ 54, 2005, 153-162.

MIZEN, P. y OPOSU-KUSI, Y. (2007). "Researching with, not on: using photography in researching street children in Accra, Ghana", Studies in qualitative Methodology, vol 8. pp: $57-81$

NOLAND, C. M. (2006). "Auto-photography as research practice: identity and selfesteem research". Journal of Research Practice 2(1): M1

PEIRCE, C. S. (2012) Obras filosóficas reunidas (2 tomos). México D.F, Fondo de Cultura Económica

PINK, S. (2008). "Mobilising visual ethnography: making routes, making place and making images". FQS: Forum: Qualitative Social Research, Volume 9, No. 3, Art. 36 September 2008

PROSSER, J. (1992). "Personal reflections on the use of photography in an ethnographic case study», British Educational Research Association Journal 18(4): http://www. education.leeds.ac.uk/\%7Eedu-jdp/image/reflec.html [3 Junio 20016].

PUTNAM, R. (2000). Bowling alone: the collapse and revival of american community. New York, Simon \& Schuster

RABADÁN CRESPO, Á.V. Y CONTRERAS PULIDO, P. "La Fotografía Participativa en el contexto socio-educativo con adolescentes". Comunicación y Hombre. 2014, $n^{\circ} 10,143-156$.

RAMIREZ CORZO, D. (2007). "La memoria de la ciudad en TAFOS: antropología visual cuando el otro tiene la cámara (portafolio fotográfico con breve prólogo)" ANTHROPOLOGICA/AÑO XXV, N. ${ }^{\circ}$ 25, diciembre de 2007, pp. 103-129

RASMUSSEN, K. (2004). "Places for children - children's places", Childhood, 11(2), 155-173.

REGUILLO CRUZ, R. (2000). Emergencia de culturas juveniles. Estrategias del desencanto. Buenos Aires. Norma. 
SHANON, K. P. \& Kinsella, E.A. (2013). "Picture this . . safety, dignity, and voice-ethical research with children: practical considerations for the reflexive researcher" Qualitative Inquiry February 1, 2013, 19, 81-90.

SORIANO AYALA, E., CALA.V.C. (2016). Fotovoz: Un método de investigación en ciencias sociales y de la salud. Madrid, Editorial Arco, Libros de La Muralla

THOMSON, P. y GUNTER, H. (2007). "The methodology of students-as-researchers: valuing and using experience and expertise to develop methods", Discourse, Vol. 28, Routledge.

VALLES, M.S. (2015). "Prácticas pioneras de archivo en la investigación sociológica cualitativa en España”. Revista Española de Investigaciones Sociológicas, 150: 173-190.

WANG, C. (1999). "Photovoice: a participatory action research strategy applied to womens's health". Journal of Women's Healath, Vol 8, No 2, 1999. Pp: 185-192.

WANG, C. \& BURRIS, M.A. (1997). "Photovoice: concept, methodology and use for participatory needs assessment", Health Education \& Behavior, vol. 24 (3), 369-387

WANG, C. C., CASH, J. L. \& POWERS, L. S. (2000). "Who knows the streets as well as the homeless?: promoting personal and action through Photovoice". Health Promotion Practice, 1, 1, 81-89

WARREN, S. (2005) "Photography and voice in critical qualitative management research" Accounting, Auditing \& Accountability Journal, 2005; 18, 6, 861-882

WORTH, S., ADAIR, J. \& CHALFEN, R. (1972). Through navajo eyes. Ao exploration in anthropology and film communication. Bloomington, University of Indiana Press.

YOUNG, L. \& BARRETT, H. (2001) "Adapting visual methods: action research with Kampala street children", Area, Volume 33, Issue 2, pages 141-152, June 2001

ZILLER, R. (1990) Photographing the self. Newbury Park, CA, Sage. 


\section{Anexo 1}

Casillero tipológico de las entrevistas a hogares en el caso español*.

\begin{tabular}{|c|c|c|c|}
\hline $\begin{array}{c}\text { Número } \\
\text { de } \\
\text { entrevista }\end{array}$ & $\begin{array}{c}\text { Sexo } \\
\text { persona } \\
\text { entrevistada }\end{array}$ & $\Gamma$ & $\begin{array}{c}\text { Segunda } \\
\text { entrevista } \\
\text { fotográfica }\end{array}$ \\
\hline UR1 & $\begin{array}{c}\text { Varón y } \\
\text { mujer }\end{array}$ & $\begin{array}{l}\text { Familia nuclear de origen ecuatoriano, } \\
\text { con hijos }\end{array}$ & Sí \\
\hline UR2 & Mujer & Familia monoparental con un hijo & Sí \\
\hline UR3 & Mujer & Familia nuclear con 4 hijos & Sí \\
\hline UR4 & Varón & $\begin{array}{c}\text { Familia nuclear de origen peruano, con } \\
\text { una hija }\end{array}$ & Sí \\
\hline UR5 & Varón & Familia nuclear con hijos & Sí \\
\hline UR6 & Mujer & $\begin{array}{c}\text { Familia nuclear con una hija, vive en los } \\
\text { nuevos desarrollos }\end{array}$ & Sí \\
\hline UR7 & Mujer & $\begin{array}{c}\text { Familia nuclear con una hija, vive en los } \\
\text { nuevos desarrollos }\end{array}$ & Sí \\
\hline UR8 & Mujer & Familia nuclear de origen marroquí & Sí \\
\hline UR9 & Varón & $\begin{array}{l}\text { Familia nuclear con un hijo, vive en los } \\
\text { nuevos desarrollos }\end{array}$ & Sí \\
\hline UR10 & Mujer & Familia monoparental con hijos & No \\
\hline UR11 & Mujer & Persona mayor que vive sola & No \\
\hline UR12 & Mujer & Familia nuclear con hijos & No \\
\hline RU1 & Mujer & Familia nuclear con hijos & Sí \\
\hline RU2 & Varón & $\begin{array}{c}\text { Familia nuclear de origen marroquí con } \\
\text { hijos }\end{array}$ & Sí \\
\hline RU3 & Varón & $\begin{array}{c}\text { Familia nuclear de origen rumano con } \\
\text { hijos }\end{array}$ & Sí \\
\hline RU4 & $\begin{array}{c}\text { Varón, mujer } \\
\text { e hija }\end{array}$ & Familia nuclear en proceso de desahucio & Sí \\
\hline RU5 & Varón & $\begin{array}{c}\text { Familia extensa, vive con la hermana y } \\
\text { sus hijos }\end{array}$ & Sí \\
\hline RU6 & Mujer e hijos & Familia extensa & Sí \\
\hline RU7 & Mujer & Familia nuclear con hijos & Sí \\
\hline RU8 & Varón & Familia nuclear con hijos & Sí \\
\hline RU9 & Mujer e hijo & Familia nuclear con hijos & Sí \\
\hline RU10 & Mujer & Familia nuclear con hijos & Sí \\
\hline RU11 & Mujer & Familia monoparental con un hijo & Sí \\
\hline RU12 & Mujer & Familia extensa de origen rumano & Sí \\
\hline
\end{tabular}

*UR hace referencia al caso urbano; RU hace referencia al caso rural 


\section{Anexo 2: Guion temático propuesto para la toma de fotografías}

\begin{tabular}{|ll|}
\hline TEMAS & ASPECTOS \\
activido de vida y & Mi familia \\
& Cosas de mi pasado \\
& Un día libre, actividades de ocio \\
& Un día de fiesta \\
& Lo que me hace sentir bien. Lo que me hace sentir mal \\
& Se nos da bien: / Se nos da mal: \\
& Cosas que hago bien y mal... \\
& Comidas y alimentos \\
& Aquello en lo que creo / Cosas en las que creo \\
& Lo que hacemos en un día normal \\
& Buscándonos la vida \\
Prácticas del hogar & Trabajando en casa \\
(cómo nos vamos & No puedo vivir sin... \\
apañando) & Puedo vivir sin... \\
Necesidades & Cosas que nos ayudan a salir adelante \\
Restricciones & No tenemos suficiente de... \\
Recursos & Éxitos y fracasos \\
Escasez & Compartiendo \\
Solidaridad & Mi barrio: lo que me gusta y lo que no me gusta \\
& Moviéndome por ahí, saliendo y entrando \\
Amigos y buena compañía \\
Gi entorno \\
(comunidad)
\end{tabular}

